\title{
Solubilization of Methylene Blue in Reversed Micelles, Effect of Water
}

\author{
Norio Miyoshi and Giiti Tomita* \\ Institute of Biophysics, Faculty of Agriculture, Kyushu University, Fukuoka 812, Japan \\ Z. Naturforsch. 35 b, 741-745 (1980); received February 20, 1980 \\ Methylene Blue, Reversed Micelles, Water Content, Solubilization \\ The solubilization of methylene blue in dodecylammonium propionate reversed micelles \\ in cyclohexane depended strongly on the solubilized water content. Methylene blue \\ solubilized in the micelle of which head groups are not completely hydrated by bound \\ water exhibited the new absorption bands at 495 and $270 \mathrm{~nm}$, but these bands did not \\ appear in the micelle containing free water. This dye had the absorption bands at 655 and \\ $290 \mathrm{~nm}$ in the latter micelle. The solubilizing process and solubilized state of methylene \\ blue in the reversed micelles were discussed with results obtained.
}

\section{Introduction}

Recently, chemical reactions of the reactants solubilized in reversed micelles are attracting many worker's attention $[1,2]$ from the interest of biomimic chemistry. The DAP reversed micelle in cyclohexane has a hydrophilic environment inside the micelle, and solubilizes various hydrophilic molecules. The DAP micelle changes its size (aggregation number) depending on the solubilized water content [3]. MB has been most commonly used for studying the photo-oxidation-reduction reaction and photosensitization reaction such as singlet oxygen production $[4,5]$ and photodynamic action $[6,7]$. The solubilized state of reactants is one of the important factors for the chemical reactions in micelle.

The present paper deals with the absorption spectrum of MB solubilized in DAP reversed micellar solutions at various water contents. The solubilizing process and solubilized state of MB were investigated in relation to the solubilized water.

\section{Materials and Methods}

MB and DAP purchased from Katayama Chemical Co. were guaranteed reagents. DAP was purified from recrystallization twice from $n$-hexane. Cyclohexane and aqueous solutions $(0.1 \mathrm{~N})$ of $\mathrm{NaOH}$ and $\mathrm{HCl}$ were obtained from Katayama Chemical Co. Laboratory-distilled water was further distilled from alkaline $\mathrm{KMnO}_{4}$ solution. Bulk pH's (3 12) in

\footnotetext{
Abbreviations: MB, methylene blue; DAP, dodecylammonium propionate.

* Reprint requests to Prof. G. Tomita.

0340-5087/80/0600-0741/\$01.00/0
}

aqueous MB solutions were adjusted with $0.1 \mathrm{~N}$ $\mathrm{NaOH}$ and $0.1 \mathrm{~N} \mathrm{HCl}$, and were measured with a pH-meter (Hitachi-Horiba, type F-7 ss).

Reversed micellar solution was prepared by dissolving DAP in cyclohexane. The DAP cyclohexanic solution was stirred in the dark at $40{ }^{\circ} \mathrm{C}$ after adding a definite amount of the concentrated aqueous MB solution (e.g., aqueous solutions of $2.0 \cdot 10^{-3}, 1.0 \cdot 10^{-3}$ and $4.0 \cdot 10^{-4} \mathrm{M} \mathrm{MB}$ for the preparation of $0.1,0.2$ and $0.5 \mathrm{M} \mathrm{H}_{2} \mathrm{O}$ DAP micellar solutions, respectively). Most of the present experiments were carried out at $\mathrm{pH} 10.0$. The monocationic blue form of $\mathrm{MB}$ is stable in the $\mathrm{pH}$ range $2 \sim 12$ [8]. The final concentration of $\mathrm{MB}$ was $3.6 \cdot 10^{-6} \mathrm{M}$ in all the sample solutions, and that of $\mathrm{H}_{2} \mathrm{O}$ was varied from 0.1 to $0.5 \mathrm{M}$.

The absorption spectrum was measured with a Hitachi spectrophotometer type 124 or 356 at $30^{\circ} \mathrm{C}$ under aerobic conditions. An optical vessel (length of optical path, $0.036 \sim 0.090 \mathrm{~mm}$ ) was used for measuring the absorption spectrum of concentrated aqueous MB solutions $\left(10^{-4} \sim 10^{-3} \mathrm{M}\right)$.

\section{Results and Discussion}

Fig. 1 shows changes in the absorbance of the MB monomer band $(655 \mathrm{~nm})$ with the time after mixing of DAP cyclohexanic and aqueous MB solutions. The absorbance unchanged with the time in the DAP micellar solution containing $0.5 \mathrm{M} \mathrm{H}_{2} \mathrm{O}$, but it decreased with the time in the DAP micellar solution containing 0.2 or $0.1 \mathrm{M} \mathrm{H}_{2} \mathrm{O}$. This absorbance decrease was more remarkable in the $0.1 \mathrm{M} \mathrm{H}_{2} \mathrm{O}$ DAP micellar solution than in the $0.2 \mathrm{M} \mathrm{H}_{2} \mathrm{O}$ DAP micellar one. The absorbance decrease with the time was observed below $0.5 \mathrm{M} \mathrm{H}_{2} \mathrm{O}$. The saturation value 


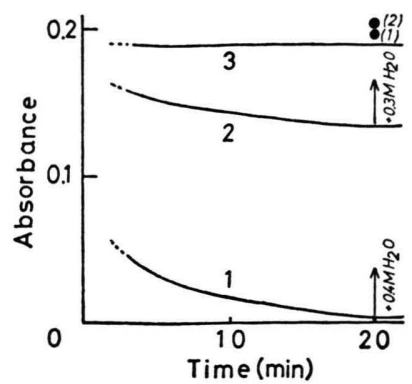

Fig. 1. Changes in the absorbance of $\mathrm{MB}$ with the time after mixing of DAP cyclohexanic and aqueous MB solutions. Concentrations of $\mathrm{MB}$ and DAP, 3.6 $10^{-6}$ and $8.0 \cdot 10^{-2} \mathrm{M}$, respectively; Curves 1,2 and 3 , DAP reversed micellar solutions containing $0.1,0.2$ and $0.5 \mathrm{M}$ $\mathrm{H}_{2} \mathrm{O}$, respectively; (1) and $(2)$, absorbances after adding $0.4 \mathrm{M} \mathrm{H}_{2} \mathrm{O}$ to Curve $\mathrm{l}$ solution and $0.3 \mathrm{M} \mathrm{H}_{2} \mathrm{O}$ to Curve 2 solution, respectively; bulk $\mathrm{pH}$ 's of aqueous $\mathrm{MB}$ solutions and $\mathrm{H}_{2} \mathrm{O}$ added, 10.0 ; temperature, $30^{\circ} \mathrm{C}$.

at 20 min was 0.002 for the $0.1 \mathrm{M} \mathrm{H}_{2} \mathrm{O}$ DAP micellar solution and 0.13 for the $0.2 \mathrm{M} \mathrm{H}_{2} \mathrm{O}$ DAP micellar one. A little higher absorbance than that in the $0.5 \mathrm{M} \mathrm{H}_{2} \mathrm{O}$ DAP micellar solution was obtained by adding $0.4 \mathrm{M} \mathrm{H}_{2} \mathrm{O}$ to the $0.1 \mathrm{M} \mathrm{H}_{2} \mathrm{O}$ DAP micellar solution or $0.3 \mathrm{M} \mathrm{H}_{2} \mathrm{O}$ to the $0.2 \mathrm{M} \mathrm{H}_{2} \mathrm{O}$ DAP micellar one at the saturation state $(20 \mathrm{~min})$, as shown by the arrow in Fig. 1. This indicates that the solubilization of MB depends on the procedure of the sample preparation. The final concentration of MB in Curves 1, 2 and 3 was equally $3.6 \cdot 10^{-6} \mathrm{M}$. The initial absorbances in these curves could not be measured, but they may highly depend on the MB concentration in its aqueous solution before mixing it with DAP cyclohexanic solution.

Fig. 2 shows the absorption spectra of MB in aqueous and DAP reversed micellar solutions. Curve 1 is the absorption spectrum of $\mathrm{MB}$ at $3 \mathrm{~min}$ after mixing of aqueous $\mathrm{MB}$ and DAP cyclohexanic solutions. The final concentrations of $\mathrm{MB}$ and $\mathrm{H}_{2} \mathrm{O}$ were $3.6 \cdot 10^{-6}$ and $0.2 \mathrm{M}$, respectively. The concentration of $\mathrm{MB}$ in the aqueous solution used for the sample preparation was $1.0 \cdot 10^{-3} \mathrm{M}$, and Curve 3 is the spectrum measured with the optical path of $0.036 \mathrm{~mm}$. The absorption bands at 655 and $600 \mathrm{~nm}$ are attributed to the monomer and dimer of MB, respectively. The dimer band in Curve 3, was higher than the monomer one, but the latter band in Curve 1 became inversely higher than the former. This indicates that large part of the dimers in aqueous solution were solubilized in DAP micelles after dissociated to monomers in the process of the DAP

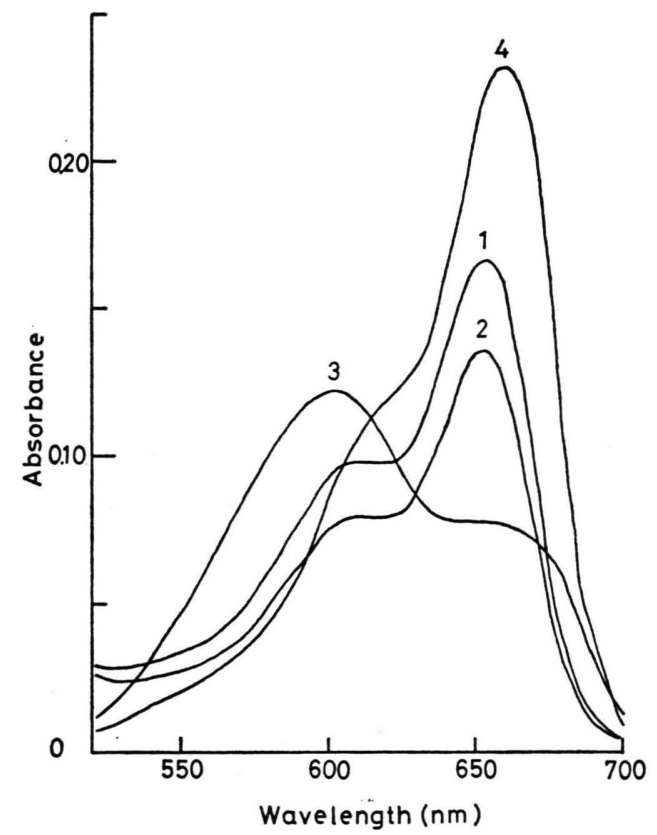

Fig. 2. Absorption spectra of MB in bulk aqueous and DAP micellar cyclohexanic solutions. Curves 1 and 2, measured at 3 and 20 min after mixing of aqueous MB and DAP cyclohexanic solutions, respectively ; Curve 3, measured with the optical path of $0.036 \mathrm{~mm}$ (aqueous solution of $1.0 \cdot 10^{-3} \mathrm{M} \mathrm{MB}$ ); Curve 4 , aqueous MB solution; final concentration of $\mathrm{MB}, 3.6 \cdot 10^{-6} \mathrm{M}$ in Curves 1,2 and 4 ; concentrations of $\mathrm{H}_{2} \mathrm{O}$ in Curves 1 and $2,0.2 \mathrm{M}$; concentration of $\mathrm{DAP}, 8.0 \cdot 10^{-2} \mathrm{M}$; bulk pH of aqueous MB solution, 10.0 ; temperature, $30^{\circ} \mathrm{C}$. The MB concentration involved in the optical path was same in Curves 1 to 4 .

micellar formation. Curve 2 is the spectrum $20 \mathrm{~min}$ after the mixing (saturation state in Fig. 1). The spectrum in the aqueous MB solution $\left(3.6 \cdot 10^{-6} \mathrm{M}\right)$ is shown as Curve 4, where most of $\mathrm{MB}$ molecules are present in the monomer form. The monomer bands in Curves 1 and 2 are blue-shifted by $5 \mathrm{~nm}$ compared with that in Curve 4. This blue-shift may be caused by the interaction between MB and the micro-field inside the micelle.

The decrease in the monomer band with the time in Fig. 1 accompanied the appearance of a new band at $495 \mathrm{~nm}$. The appearance of the $495 \mathrm{~nm}$ band was more pronounced in DAP micellar solution with lesser $\mathrm{H}_{2} \mathrm{O}$ content as shown in Fig. 3. The monomer and dimer bands in the visible region almost disappeared in the $0.1 \mathrm{M} \mathrm{H}_{2} \mathrm{O}$ DAP micellar solution. Further, the $290 \mathrm{~nm}$ band in aqueous MB solution was replaced by a new broad band at $270 \mathrm{~nm}$ 


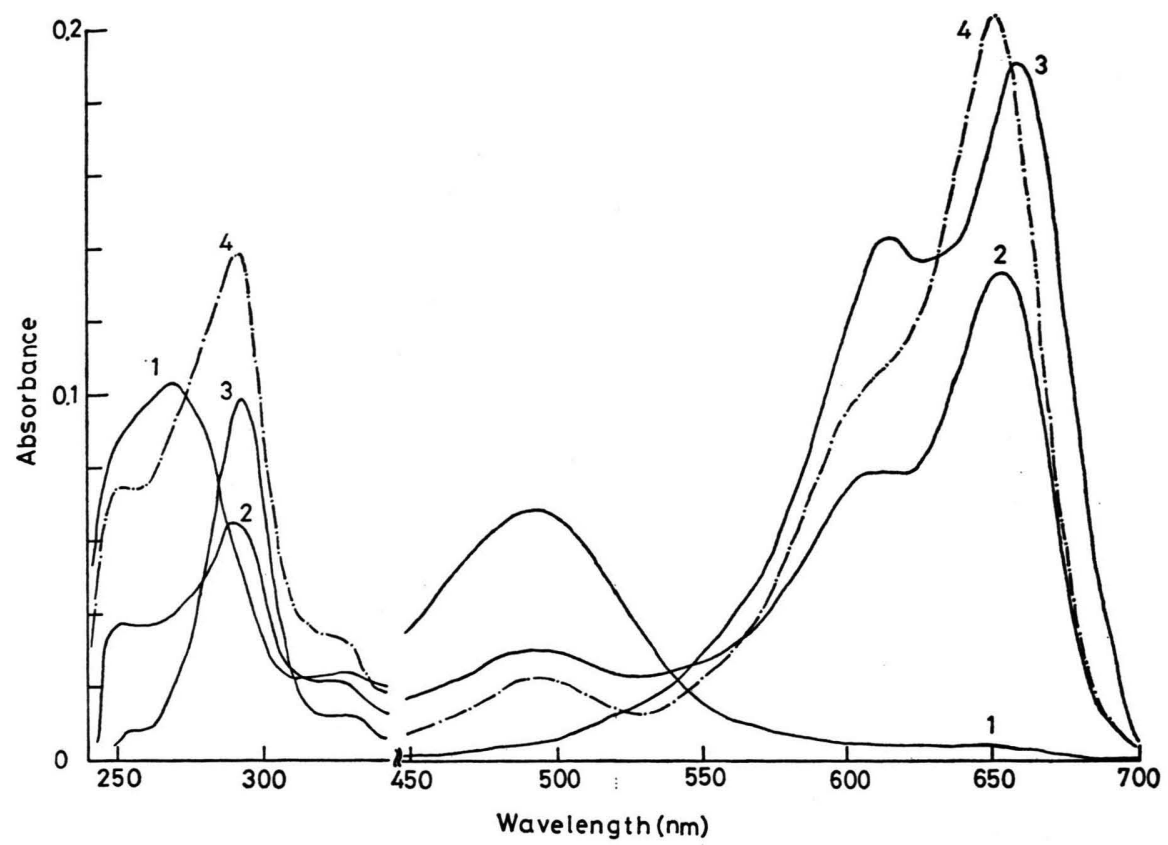

Fig. 3. Absorption spectra of $\mathrm{MB}$ in $\mathrm{DAP}$ reversed micellar solutions at various $\mathrm{H}_{2} \mathrm{O}$ concentrations 20 min after mixing of aqueous MB and DAP cyclohexanic solutions. Concentrations of MB and DAP, 3.6 $10^{-6}$ and $8.0 \cdot 10^{-2} \mathrm{M}$, respectively; Curves 1,2 and 3 , solubilized $\mathrm{H}_{2} \mathrm{O}$ of $0.1,0.2$ and $0.5 \mathrm{M}$, respectively; Curve 4, after adding $0.4 \mathrm{M} \mathrm{H}_{2} \mathrm{O}$ to Curve $\mathrm{l}$ solution; bulk $\mathrm{pH}$ 's of aqueous $\mathrm{MB}$ solutions and $\mathrm{H}_{2} \mathrm{O}$ added, 10.0 ; temperature, $30^{\circ} \mathrm{C}$.

(Curve 1). In the 0.2 $\mathrm{M} \mathrm{H}_{2} \mathrm{O}$ DAP micellar solution, the monomer, dimer and $290 \mathrm{~nm}$ bands were still present (Curve 2). The $495 \mathrm{~nm}$ band did not appear in the $0.5 \mathrm{M} \mathrm{H}_{2} \mathrm{O}$ DAP micellar solution, and the content ratio of dimer to monomer was comparatively high compared with that in the $0.2 \mathrm{M} \mathrm{H}_{2} \mathrm{O}$ DAP micellar solution (Curve 3).

Next, when $0.4 \mathrm{M} \mathrm{H}_{2} \mathrm{O}$ was added to the Curve 1 solution, the monomer $(652 \mathrm{~nm})$ and $290 \mathrm{~nm}$ bands developed remarkably (Curve 4). But the dimer band was much weaker than that in Curve 3 . The shape of Curve 4 quite resembled to that of Curve 4 (aqueous MB solution) in Fig. 2. Namely, Curve 3 was not obtained by adding $0.4 \mathrm{M} \mathrm{H}_{2} \mathrm{O}$ to the Curve 1 solution. This indicates that the dimers were bound to $0.5 \mathrm{M} \mathrm{H}_{2} \mathrm{O}$ DAP micelles as monomer on the formation of the $0.5 \mathrm{M} \mathrm{H}_{2} \mathrm{O}$ DAP micelle from the $0.1 \mathrm{M} \mathrm{H}_{2} \mathrm{O}$ DAP micelle (redistribution of MB in DAP micelles). The absorbances at $495 \mathrm{~nm}$ $\left(\mathrm{A}_{495}\right)$ and monomer $\left(\mathrm{A}_{655}\right)$ bands in DAP micellar solutions at various water contents are shown in Fig. 4. The absorbance was measured 20 min after mixing of aqueous $\mathrm{MB}$ and DAP cyclohexanic solutions. $\mathrm{A}_{495}$ decreased rapidly with increasing the water content, but $A_{655}$ inversely showed a rapid increase.

$\mathrm{A}_{655}$ and $\mathrm{A}_{495}$ are plotted in Fig. 5 at various bulk $\mathrm{pH}$ 's in $0.2 \mathrm{M} \mathrm{H}_{2} \mathrm{O}$ DAP micellar solutions. At lower $\mathrm{pH}$ 's below $5, \mathrm{~A}_{655}$ had a high constant value but $\mathrm{A}_{495}$ vanished. At higher $\mathrm{pH}$ 's above 5, $\mathrm{A}_{655}$ showed a slight decrease and $\mathrm{A}_{495}$ did a gradual

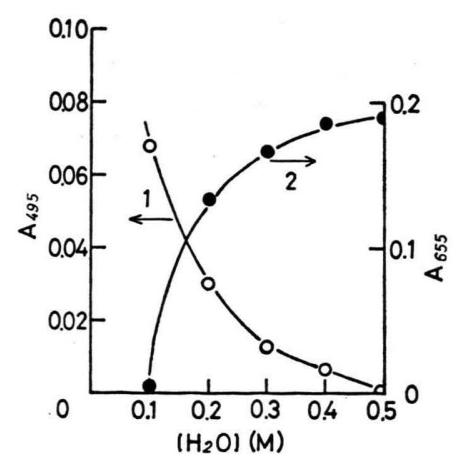

Fig. 4. Absorbances at $495\left(\mathrm{~A}_{495}\right)$ and $655\left(\mathrm{~A}_{655}\right) \mathrm{nm}$ bands of $\mathrm{MB}$ as a function of $\mathrm{H}_{2} \mathrm{O}$ concentration. Concentrations of $\mathrm{MB}$ and DAP, 3.6 $10^{-6}$ and $8.0 \cdot 10^{-2} \mathrm{M}$, respectively; Curves 1 and $2, \mathrm{~A}_{495}$ and $\mathrm{A}_{655}$, respectively; bulk $\mathrm{pH}$ 's of aqueous MB solutions and $\mathrm{H}_{2} \mathrm{O}$ added, 10.0 ; temperature, $30^{\circ} \mathrm{C}$. 


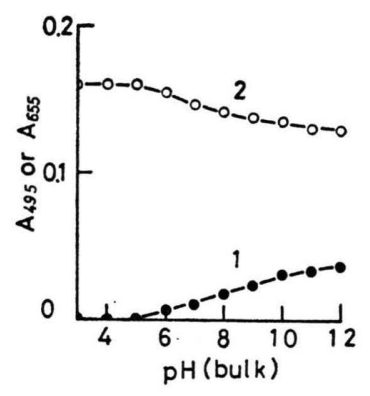

Fig. 5. Absorbances at $495\left(\mathrm{~A}_{495}\right)$ and $655\left(\mathrm{~A}_{655}\right) \mathrm{nm}$ bands of MB at various bulk pH's. Concentrations of $\mathrm{MB}, \mathrm{DAP}$ and $\mathrm{H}_{2} \mathrm{O}, 3.6 \cdot 10^{-6}, 8.0 \cdot 10^{-2}$ and $0.2 \mathrm{M}$, respectively; Curves 1 and $2, A_{495}$ and $A_{655}$, respectively; temperature, $30^{\circ} \mathrm{C}$.

increase. These changes may be related to the binding state of MB which depends on the dissociation state of the head groups (amine and hydroxyl) in DAP reversed micelles.

The results obtained are summarized as a diagram shown in Fig. 6. On the formation of the reversed micelles containing low concentrations of $\mathrm{H}_{2} \mathrm{O}$ such as 0.1 and $0.2 \mathrm{M}, \mathrm{MB}$ molecules in aqueous solution are fractionated by DAP micelles. However, large part of dimers present in aqueous solution dissociate to monomers when solubilized in the micelles. Some monomers may be stably bound to the DAP micelles about 20 min after mixing of aqueous MB and DAP cyclohexanic solutions under the present experimental conditions. The state of MB molecules in the $0.5 \mathrm{M} \mathrm{H}_{2} \mathrm{O}$ DAP micelles which was obtained by adding $\mathrm{H}_{2} \mathrm{O}$ to $0.1 \mathrm{M} \mathrm{H}_{2} \mathrm{O}$ or $0.2 \mathrm{M} \mathrm{H}_{2} \mathrm{O}$ DAP micelles was different from that in the $0.5 \mathrm{M} \mathrm{H}_{2} \mathrm{O}$ DAP micelles prepared originally as stated above.

Correl et al. [3] described that the aggregation number of DAP micelle is strongly dependent on the solubilized water content. Parameters for $0.08 \mathrm{M}$ DAP reversed micelles were obtained at various solubilized $\mathrm{H}_{2} \mathrm{O}$ contents from the data of Correl et al. These are given in Table I. The average

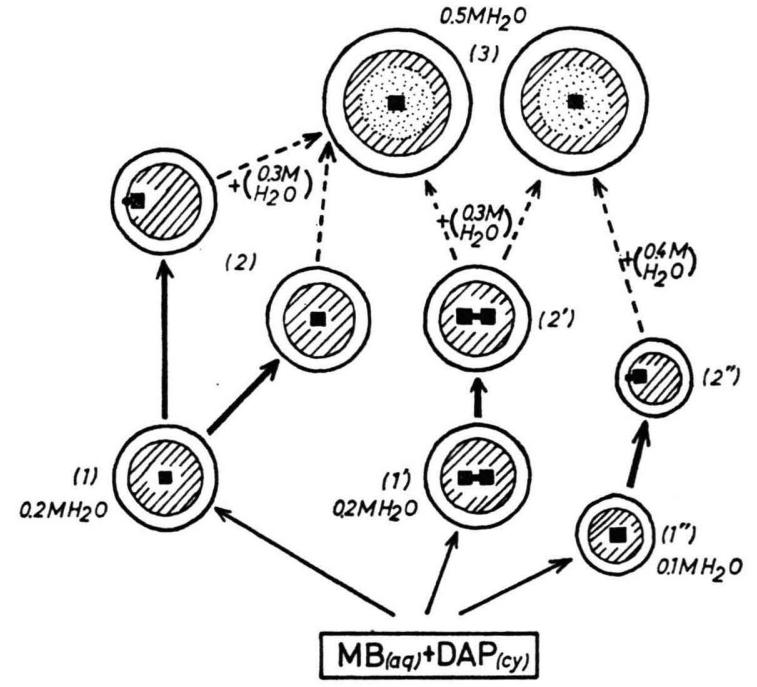

Fig. 6. A diagram for the solubilization of MB in DAP reversed micelles. States of $(1),\left(1^{\prime}\right)$ and $\left(2^{\prime \prime}\right)$, immediately after mixing of aqueous $\mathrm{MB}$ and DAP cyclohexanic solutions, respectively; states of $(2),\left(2^{\prime}\right)$ and $\left(2^{\prime \prime}\right)$, after solubilization of MB in DAP micelles; shaded portion, bound water; dotted portion, free water; a, MB monomer; [-a, MB dimer.

number of $\mathrm{H}_{2} \mathrm{O}$ molecules per one DAP micelle increases with increasing the solubilized $\mathrm{H}_{2} \mathrm{O}$ concentration. Correl et al. assumed that one head group binds two $\mathrm{H}_{2} \mathrm{O}$ molecules at maximum as bound water and $\mathrm{H}_{2} \mathrm{O}$ molecules more than two are bound as free water inside the micelle. According to this assumption, the free water appeares in DAP micelles containing $\mathrm{H}_{2} \mathrm{O}$ more than about $0.3 \mathrm{M}$ as seen in Table I. Further, about 70 and $40 \%$ of the head groups are not hydrated with bound water in 0.1 and $0.2 \mathrm{M} \mathrm{H}_{2} \mathrm{O}$ DAP micellar solutions, respectively. Accordingly, the appearance of the $495 \mathrm{~nm}$ band depending on the solubilized $\mathrm{H}_{2} \mathrm{O}$ concentration (Fig. 4) is explained as follows. After mixing of aqueous $\mathrm{MB}$ and DAP cyclohexanic solutions, DAP

Table I. Parameters for $0.08 \mathrm{M}$ DAP reversed micelles at various water contents. $\mathrm{N}$, average aggregation number of DAP micelle from the data obtained by Correl et al. [3]; n, number of head groups (amine and hydroxyl) in one DAP micelle; $\mathrm{C}_{M}$, micellar concentration; $\left.\left[\mathrm{H}_{2} \mathrm{O}\right] / \mathrm{C}_{M} \cdot n\right)$, average number of $\mathrm{H}_{2} \mathrm{O}$ molecules bound per head group.

\begin{tabular}{lllllll}
\hline$\left[\mathrm{H}_{2} \mathrm{O}\right](\mathrm{M})$ & 0.1 & 0.2 & 0.3 & 0.4 & 0.5 & 0.6 \\
\hline $\mathrm{N}$ & 6 & $1.1 \cdot 10$ & $2.0 \cdot 10$ & $3.5 \cdot 10$ & $5.4 \cdot 10$ & $7.7 \cdot 10$ \\
$\mathrm{n}$ & $1.2 \cdot 10$ & $2.2 \cdot 10$ & $4.0 \cdot 10$ & $7.0 \cdot 10$ & $1.1 \cdot 10^{2}$ & $1.5 \cdot 10^{2}$ \\
$\mathrm{C}_{\mathrm{M}}(\mathrm{M})$ & $1.3 \cdot 10^{-2}$ & $7.3 \cdot 10^{-3}$ & $4.0 \cdot 10^{-3}$ & $2.3 \cdot 10^{-3}$ & $1.5 \cdot 10^{-3}$ & $1.0 \cdot 10^{-3}$ \\
{$\left[\mathrm{H}_{2} \mathrm{O}\right] / \mathrm{C}_{\mathbf{M}}$} & 7.7 & $2.7 \cdot 10$ & $7.5 \cdot 10$ & $1.7 \cdot 10^{2}$ & $3.3 \cdot 10^{2}$ & $6.0 \cdot 10^{2}$ \\
{$\left[\mathrm{H}_{2} \mathrm{O}\right] /\left(\mathrm{C}_{\mathbf{M}} \cdot \mathrm{n}\right)$} & 0.6 & 1.2 & 1.8 & 2.5 & 3.0 & 3.9 \\
\hline
\end{tabular}


molecules create micelles solubilizing aqueous MB solution. MB dimers are solubilized in DAP micelles directly or after being dissociated to the monomers. The water molecules solvating MB molecule may escape to hydrate the head groups. The naked MB molecule may be bound to the head group unhydrated by bound water. This binding might be caused by the Coulomb and hydrogen bonding interactions as shown in Fig. 7. The binding state created by the proton transfer from amino head

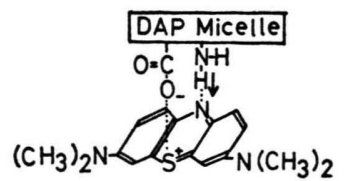

Fig. 7. A model for the binding state of MB inside DAP micelle having the $495 \mathrm{~nm}$ band. Arrow, proton displacement. group to MB molecule as shown by the arrow might be responsible for the $495 \mathrm{~nm}$ band. This binding interaction may be lost in the free water range above $0.4 \mathrm{M}$ due to the hydrations of head group and MB molecule.

In conclusion, the solubilization of $\mathrm{MB}$ in DAP reversed micelles depended strongly on the concentration of solubilized $\mathrm{H}_{2} \mathrm{O}$. The time after mixing of aqueous MB and DAP cyclohexanic solutions and the procedure of the sample preparation were also important factors, since the solubilization of MB and the micellar formation of DAP are entangled each other. The detailed binding state of $\mathrm{MB}$ molecule to DAP micelle is still open to be made clear up in future investigation.
[1] J. H. Fendler, Acc. Chem. Res. 9, 153 (1976).

[2] H. Kondo, K. Fujiki, and J. Sunamoto, J. Org. Chem. 43, 3584 (1978).

[3] G. D. Correl, R. N. Cheser, III, F. Nome, and J. H. Fendler, J. Am. Chem. Soc. 100, 1254 (1978).

[4] P. B. Merkel and D. W. Kearns, J. Am. Chem. Soc. 90, 6233 (1968).
[5] A. A. Gorman, G. Lovering, and M. A. Rogers, Photochem. Photobiol. 23, 399 (1976).

[6] H. Singh and D. Ewing, Photochem. Photobiol. 28, 547 (1978).

[7] L. S. Jahnke and A. W. Frenkel, Photochem. Photobiol. 28, 517 (1978).

[8] E. Rabinowitch and L. F. Epstein, Ind. Eng. Chem. 63, 69 (1941). 